\title{
Development and testing of INSPIRE themes Addresses (AD) and Administrative Units (AU) managed by COSMC
}

\author{
Michal Med, Petr Souček \\ The Czech Office for Surveying, Mapping and Cadastre (COSMC) \\ Prague, the Czech Republic \\ michal.med@cuzk.cz, petr.soucek@cuzk.cz
}

\begin{abstract}
Main content of this article is to describe implementing INSPIRE themes Addresses and Administrative Units in Czech Republic. Themes were implemented by Czech Office for Surveying, Mapping and Cadastre. Implementation contains developing GML files with data and designing its structure, developing and testing of INSPIRE services and preparing metadata for data and services. Besides harmonised INSPIRE themes COSMC manages also non-harmonised themes Cadastral map (KM) and Units eXtended (UX).
\end{abstract}

Keywords: INSPIRE, Cadastre, Addresses, Cadastral Parcels, Administrative Units, Buildings, Metadata, RÚIAN, services, WMS, WFS, GML

\section{Introduction}

INSPIRE - INfrastructure for SPatial InfoRmation in Europe is a Directive of European Commission and Council, which was transposed into Czech legislation in 2009 by the law number 380/2009 Col., which amends laws number 123/1998 Col., on the right to information about environment and number 200/1994 Col., about surveying.

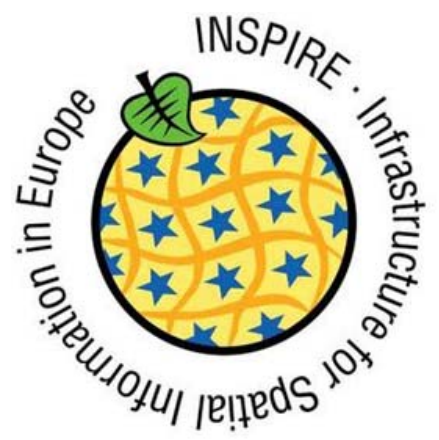

Figure 1: INSPIRE logo

From the law number 123/1998 Col. come (among others) following duties:

- create and manage metadata for spatial data files and for network services, 
- harmonise spatial data sets according to the Directive,

- create interoperable network services.

Important part of implementation is also giving information on implementation to public. All basic information about implementation of data and services are available at geoportal $\mathrm{COSMC}^{1}$ in czech and in english in a bookmark INSPIRE. Pages for themes Cadastral Parcels $(\mathrm{CP})$, Addresses (AD) and Administrative Units (AU) have a special look and structure. It was designed for better intelligibility of data and services for users. From the geoportal, there is also possibility of downloading data and access network services. Data, services and informations are available on national INSPIRE geoportal ${ }^{2}$, administered by CENIA, Czech environmental agency.

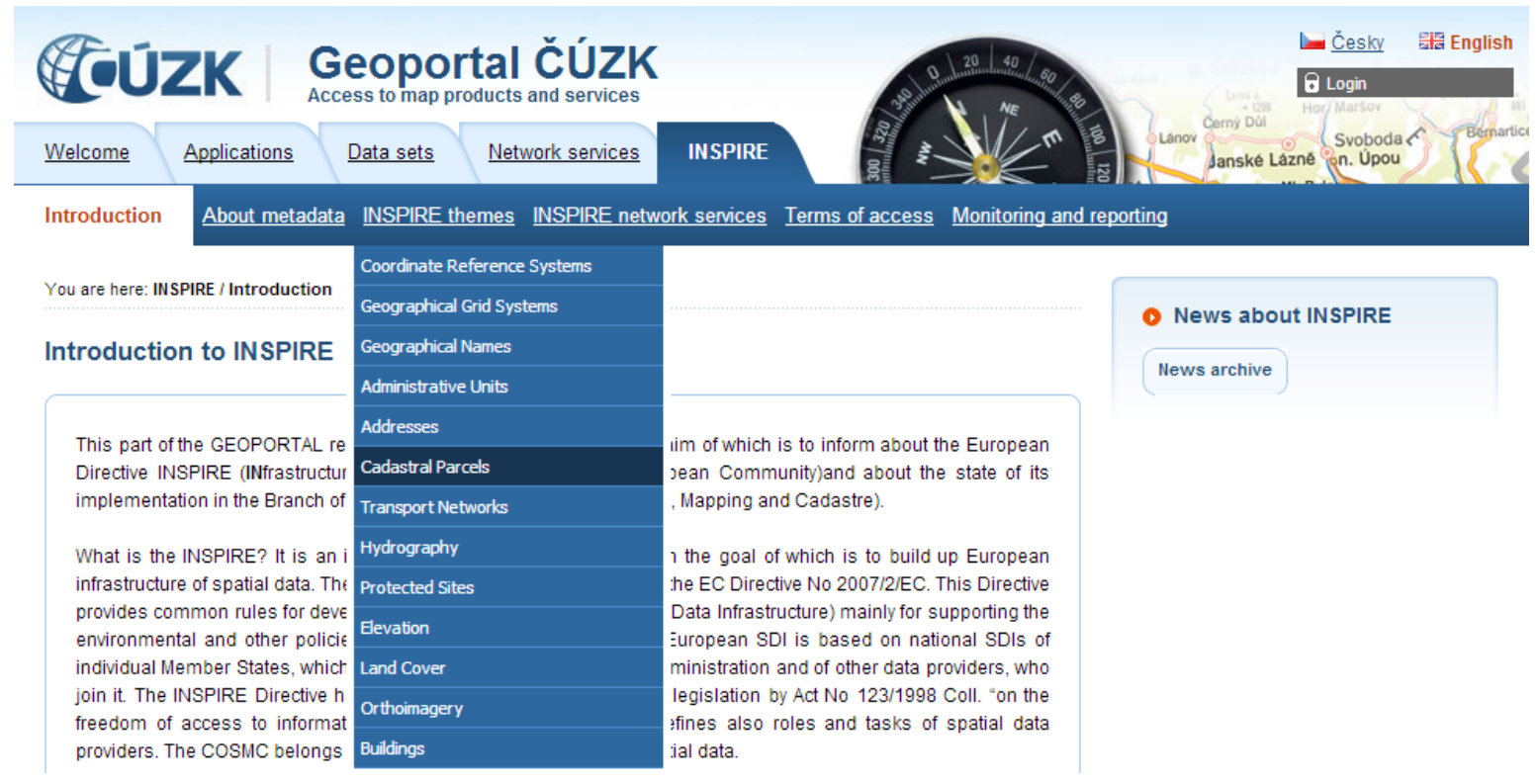

Figure 2: COSMC geoportal

This geoportal should collect all datasets relevant to INSPIRE including services and metadata. Unfornutelly, at least in my opinion, it's used more like trash can for all data sets which contain some part of data even distantly similar to those relevant to INSPIRE.

Searching of data and series is mediated through INSPIRE Discovery services. Discovery services are searching in metadata, specifically in keyword elements. Every provider can write into keywords anything he wants. That could be, and is, a problem. For accesing all data and services managed by COSMC, either by Section of central database or by Surveying Office, I conclusively recommend using the geoportal COSMC.

\section{Implementation}

During implementation of INSPIRE themes Addresses and Administrative Units, datasets and services harmonised by Implementation rules of INSPIRE Directive were designed, developed

\footnotetext{
${ }^{1}$ http://geoportal.cuzk.cz/

${ }^{2}$ http://geoportal.gov.cz/
} 
and tested. Technical guidances for services and Data specifications were used during the implementation. Next step was making of metadata records. Metadata records serve as a description of data or services, not only human readible, but primarily computer readable.

I am personally engaged in a process of implementation since making of metadata records for data of the theme Cadastral Parcels. Themes Addresses and Administrative Units were implemented from the beggining to the very end with my participation. During implementation of themes Addresses and Administrative Units, metadata and data of the theme Cadastral Parcels were revised. This implementation took place in a few steps in the following order:

- analysis of Data specifications and Technical guidances INSPIRE,

- analysis of data in databases of COSMC,

- design of a data files structure,

- design of supported operations and planned limits for view and download services,

- creating of metadata records,

- testing and analysis of prepared data and services,

- revision of data files and services,

- revision of metadata,

- creating of promotional materials,

- publishing of data, services and metadata on the web http://services.cuzk.cz/,

- publishing of promotional materials on the web http://geoportal.cuzk.cz/.

In the future, Section of central database is going to continue in the implementation of INSPIRE Directive with the theme Buildings (BU). Concurrently with implementation of next INSPIRE theme, revisiones of already done themes are taking place in legislation. Revisions are based on experience and users feedback.

\subsection{Data}

Preparation of data is based on Data specifications on themes. Preparation of data is devided into three phases. In the first one, I have studied Data specifications on Addresses and Administrative Units. Second step was to analyse corresponding data in COSMC databases ${ }^{3}$. During the analysis it's necessary to decide which data from database are suitable to data structure according to the specification. For that purpose, I have made schemes of usage. In the third phase I have prepared sample file in GML 3.2.1 format. The sample file for each theme was sent to the firm Geovap, the developer of software Marushka ${ }^{\circledR}$, which mediates generating of predefined GML files according to sample file for each theme.

The basic dispensing unit is different for each theme. For the theme Cadastral Parcels, there is one predefined file for each cadastral zoning. Addresses have one file for each municipality and all data for the theme Administrative Units are distributed in only one file for the whole

\footnotetext{
${ }^{3}$ ISKN - Information system of cadastre of real estates, ISÚI - Information system of territorrial identification, ZABAGED - Fundamental Base of Geographic Data
} 


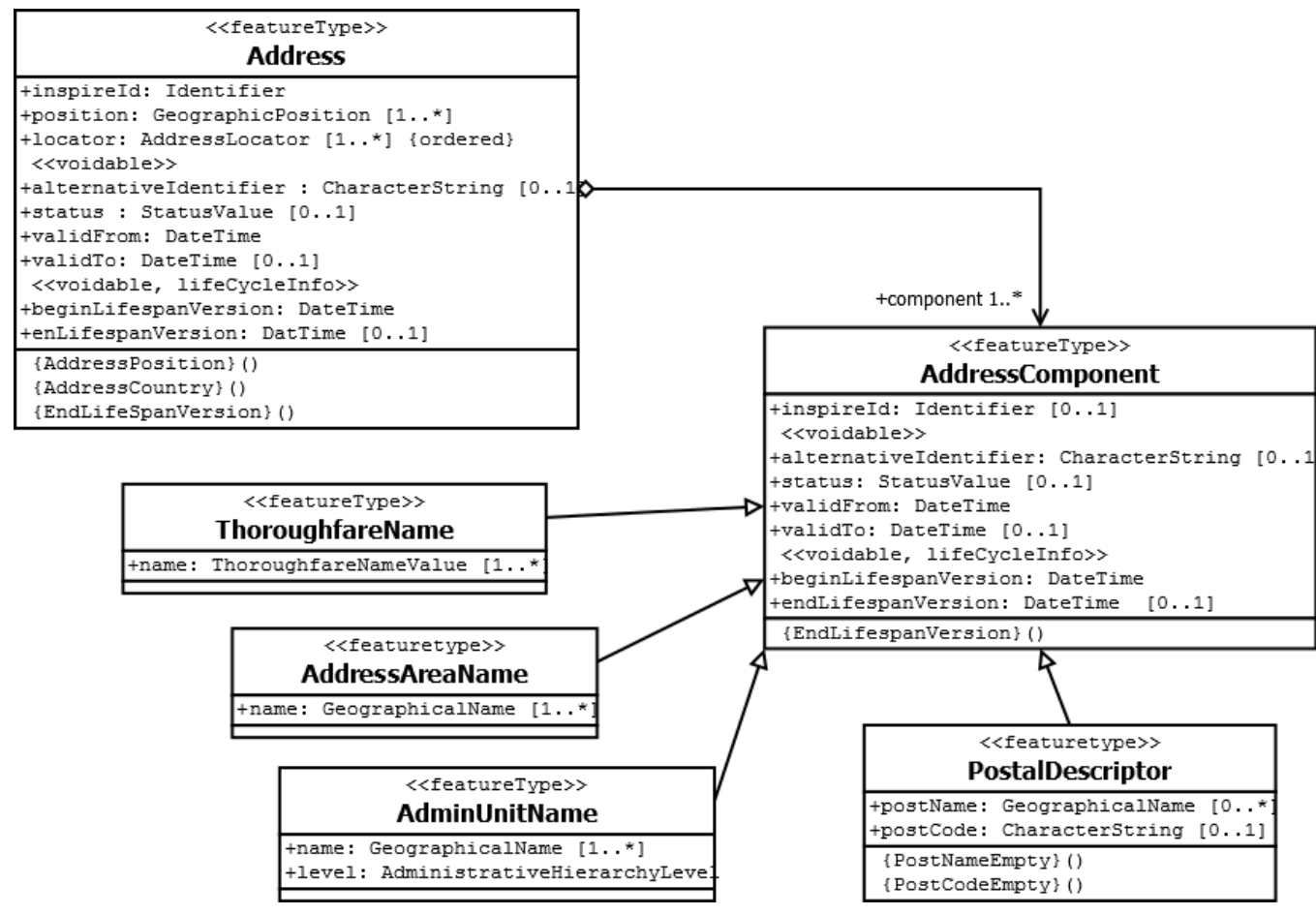

Figure 3: UML diagram of Application scheme on theme Addresses

Czech Republic. Predefined files are generated daily and are available for free on the page http://services.cuzk.cz/gml/inspire.

Marushka ${ }^{\circledR}$ software, besides providing of predefined files, also mediates INSPIRE harmonised download and view services according to the INSPIRE Technical guidance for services. These services are realised through OGC and ISO standards about WMS 1.3.0 and WFS 2.0.0.

\subsection{Services}

According to the INSPIRE Directive there is five types of services, which has to be provided for rightful implementation. These services shall be implemented:

- Discovery services - allow to search for data ad services according to keywords in metadata,

- View services - allow viewing data through Web Mapping Services in version 1.3.0,

- Download services - allow donwloading data through Web Feature Service in version 3.0 or through predefined GML files,

- Trensformation services - allow transformation of spatial data,

- Startup services - allow access for other types of services.

From the INSPIRE implementations point of view I was especially interested about implementation of download and view services, which allow direct access to the data. Data are continually updated in Publication Database. Sources of the data of Publication Database 
are ISÚI and ISKN. Data are essentially current, as the age of data two hours are featured.

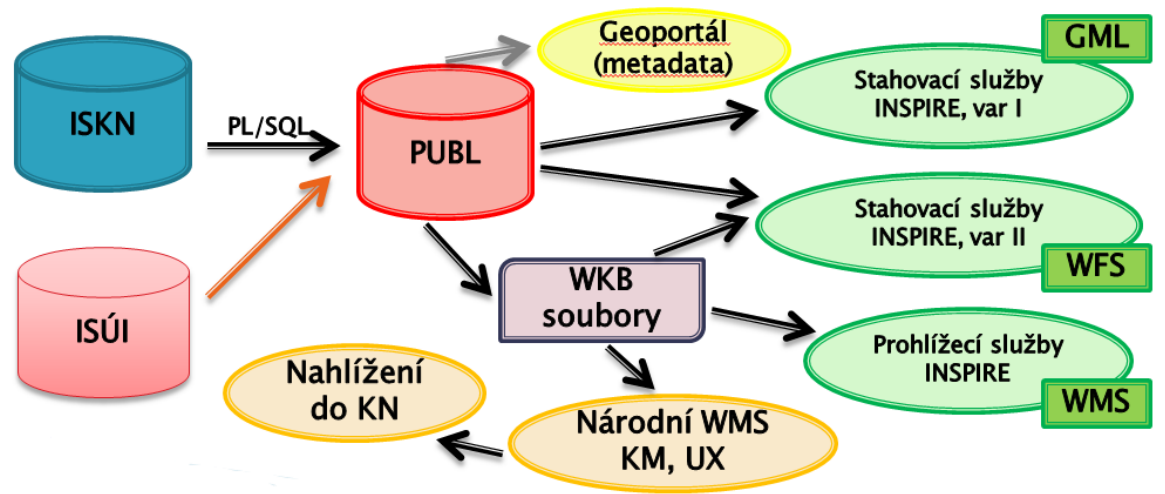

Figure 4: Process of managing data from databases ISÚI and ISKN for predefined GML files and WMS and WFS services Source: Ing. Petr Souček, Ph.D.

INSPIRE View services are realised through Web Mapping Service 1.3.0. Besides this version, older version 1.1.1 is also supported, but not forced by INSPIRE Directive. Access point for service is web address according to this model: http://services.cuzk.cz/wms/inspire[theme]-wms . asp?. For example, view service for the theme Addresses has acces point on address http://services.cuzk.cz/wms/inspire-ad-wms.asp?. In order to simplify accessing data I have created a set of guidelines for using WMS services. Ther is one document for each theme:

- http://services.cuzk.cz/doc/inspire-ad-view.pdf - for Addresses,

- http://services.cuzk.cz/doc/inspire-au-view.pdf - for Administrative Units,

- http://services.cuzk.cz/doc/inspire-cp-view.pdf - for Parcels,

which contains list of available layers, supported coordinate systems and samples of requests.

Download services are realised according to Technical guidelines via WFS in version 2.0.0 and through predefined data files in GML format. Older versions of WFS aren't supported. Problem is, that WFS 2.0.0 is not supported by most software. Only one I know about, that supports this service is QGIS. Access is mediated through plugin WFS 2.0 written by Jürgen Weichand. Manual on downloading and using this plugin, including basic examples of working with it, is to found on this page: http://services.cuzk.cz/doc/manual-wfs20-qgis.pdf.

Access point for Web Feature Service is web page according to the model http://services . cuzk.cz/wfs/inspire-[theme]-wfs .asp?. Here's an example for Addresses: http://services . cuzk.cz/wfs/inspire-ad-wfs.asp?. Same as for WMS, for WFS I have created manuals too. They contain information about structure of data available through Web Feature Service and about the usage of this service. There is one document for each theme at the following addresses:

- http://services.cuzk.cz/doc/inspire-ad-download.pdf - for Addresses,

- http://services.cuzk.cz/doc/inspire-au-download.pdf - for Administrative Units, 
- http://services.cuzk.cz/doc/inspire-cp-download.pdf - for Parcels.

Besides on-line access to data there is also a possibility to get a data through predefined GML files as described before.

\subsection{Metadata}

Metadata harmonised to INSPIRE has to follow Technical guideline for metadata. Its newest version (1.3) has been released on the 6th of November 2013. Metadata published by COSMC within INSPIRE is possible to divide into two parts. First one could be called "static", second one "dynamic". Static metadata include metadata for Series of INSPIRE datasets, metadata for INSPIRE Download services and metadata for INSPIRE View services. Dynamic metadata include getCapabilities documents for WMS and WFS, getFeatureInfo document, describeStoredQueries and other documents relative to network services. As the INSPIRE harmonised metadata are considered all metadata from the first category.

Technical guideline for metadata comes from technical norms ISO 19115 and ISO 19119 and National metadata profile and Metadata profile of COSMC also follow these norms. Metadata profile of COSMC includes everything what is required by INSPIRE Technical guidelines and National metadata profile and even more. Therefore I have used COSMC profile while I was creating metadata for INSPIRE themes.

All metadata has an identifier, which is unique in the scope of COSMC namespace. Combination of an identifier and namespace identifies metada record uniquely in the scope of the whole INSPIRE. Metadata describe service or metadata they are attached to. Besides description info they contain keywords. Keywords serves for discovering products through INSPIRE Discovery services. Every metadata record has a keyword according to GEMET thesaurus. For the data metadata, GEMET keyword serves as an identifier of the INSPIRE theme. Services metadata have an additional GEMET keyword which serves as an identifier of the type of INSPIRE service.

Other keywords should come from Vocabulary of COSMC, but not all INSPIRE related keywords are included. Currently we have initialized negotiations with Terminological commision about adding new keywords to the Vocabulary. Most of them are related to INSPIRE and Basic registers.

Metadata also include information about Data quality and its testing. For data and services, only tests used were on INSPIRE consistency and data completeness.

\section{What's next?}

By publishing data, metadata and services, implementation of INSPIRE isn't done yet. We have found a lot of mistakes and comments during implementation and I believe that so did most of European developers and analysts working on implementation of INSPIRE. Thats a reason why Maintanatce and Implementation Group (MIG) and Pool of Experts were founded. Ing. Jiří Poláček, CSc. is MIG member and both authors of this article are members of Pool of Experts. Implementation of INSPIRE is moving from the opening phase into the maintanance phase.

Within improvement of INSPIRE data and services it's really important users' feedback and 
continual development of data,, metadata and services. During my work on Addresses and Administrative Units I have revised metadata for Cadastral Parcels, which were published more than a year ago.

In the same time, interoperability of data and services between neighbour countries is going to be tested. Czech data and services are now tested together with Slovaks and cooperation with other neighbour states will follow.

\section{References}

[1] Poláček, J. Souček, P.: Implementing INSPIRE for the Czech Cadastre of Real Estates, Geoinformatics FCE CTU 8, 2012, pp. 9-16. [Online] [Cited: December 27, 2013.] http: //geoinformatics.fsv.cvut.cz/pdf/geoinformatics-fce-ctu-2012-08.pdf 